\title{
Depth of the Gingival Sulcus Surrounding Young Permanent Teeth
}

\author{
BY EDWIN J. FUDER, D.D.s. * AND HOMER C. JAMISON, D.D.s., DR.P.H., ** \\ ANN ARBOR, MICHIGAN
}

I $\mathrm{N}$ almost every phase of dentistry, the operator must concern himself with the gingival sulcus $* *$ sometime during his procedures. One of the important characteristics of this sulcus is its depth; hence, the operator must become concerned and informed about the changes which occur in the sulcus during life.

An investigation was undertaken with the following objectives in mind: (1) determine the mean depth of the gingival sulcus of labial, lingual and approximating surfaces of young human permanent teeth, excluding third molars, and (2) determine whether the depth of the sulcus changes during adolescence.

\section{REVIEW OF THE LITERATURE}

Before 1921, it was accepted that as soon as the tip of a tooth had broken through the epithelium into the oral cavity the base of the gingival sulcus was located at the cemento-enamel junction. ${ }^{2,15}$ The depth of the sulcus, therefore, could vary from many millimeters to a few millimeters as the tooth continued to erupt into occlusion.

In 1921 , Gottlieb 7,8 concluded that the epithelium of the gingival crevice was attached to the enamel of the tooth by means of the primary enamel membrane. This at-

\footnotetext{
"Instructor in Dentistry, The University of Michigan, School of Dentistry, Ann Arbor, Mich.

**Associate Professor of Dentistry, The University of Alabama Medical Center, Birmingham, Alabama.

$* *$ The gingival sulcus also may be known as the gingival crevice, gingival through, or subgingival space. Gingival pocket, however, in correct usage, refers to a pathologic sulcus about a tooth, deeper than the normal sulcus. (Arey, L. B., ed. Dorland's Illustrated Medical Dictionary. 23rd ed. Philadelphia, Saunders, 1957. XVII 1598 p.)
}

tachment was thought to mark the bottom of the gingival sulcus which, then, could not be situated at the cemento-enamel junction but had to be located on the surface of the enamel of the crown of the tooth. Other investigators ${ }^{11,16,17,19,20}$ agreed with Gottlieb's concept of a shallow gingival sulcus.

Kronfeld ${ }^{11}$ stated that neither age nor the location of the gingival crevice on the surface of the tooth had any effect on the depth of the sulcus. Miller ${ }^{13}$ concurred with the preceding investigators in regard to the depth of the sulcus that surrounds adults' teeth. Miller, however, stated that the depth of the sulcus, surrounding erupting teeth and young permanent teeth usually was two to three millimeters, and he reported depths of up to six millimeters for the sulci of the labial surfaces of the maxillary incisors. Since Miller agreed with Gottlieb on the existence of an epithelial attachment on enamel, he presumed, therefore, that "the deeper sulcus in children is probably due to the lagging of active eruption behind the passive."

In clinical observations of the depth and location of the bottom of the gingival sulcus, Waerhaug ${ }^{22}$ found that the average depth of the sulcus was about four millimeters and that the bottom of the sulcus ended at the cemento-enamel junction. In a duplication of the investigation of Waerhaug, Orban, et al., ${ }^{18}$ found the bottom of the gingival sulcus to be one millimeter below the free gingival margin in a histological specimen. As the blade was inserted deeper, it progressed in epithelium between a layer of cells still attached to the enamel and the remainder of the epithelial attachment. Bödecker and Applebaum $^{3}$ reported similar findings. 
Orban, et al., ${ }^{18}$ criticized Waerhaug sharply for stating that as soon as a tooth erupts into the mouth, the crevice reaches to the cemento-enamel junction. Orban and colleagues maintained, in dogs, that even after the tooth has erupted into the oral cavity, amelogenesis continued in the gingival areas of the crown and that the ameloblasts and enamel rods formed an organic union while the phase completed. However, according to Wheeler ${ }^{23}$ human crowns of the permanent teeth are completed three years or more before the teeth erupt.

Bödecker and Lefkowitz ${ }^{4}$ concluded that the epithelial attachment could not be defined clinically, and that the depth of the crevice could be measured only to the beginning of the attachment by connective tissue. Zander ${ }^{24}$ reported that the bottom of the gingival sulcus and the most apical epithelial cells were found to be at or near the cemento-enamel junction.

Three of the current textbooks on periodontology ${ }^{1,5,6}$ state that the gingival sulcus is shallow and usually ranges in depth from 0.5-1.8 millimeters. Much of the literature cited by these writers refers to the publications of Gottlieb ${ }^{7}$ and Orban and Kohler. ${ }^{16}$ Beube $^{1}$ and Goldman ${ }^{6}$ stated that the gingival sulcus was deeper in young persons than during later periods in life.

Disagreement became apparent among investigators regarding both the depth of the sulcus and the changes which occur in depth during adolescence. Further study, therefore, appeared important.

\section{MATERIALS AND INVESTIGATIVE METHODS}

The School of Public Health of The University of Michigan began planning an extensive study of health in an entire community in 1956. The city of Tecumseh, Michigan, and the surrounding area was chosen as the site for the study. The area, of about 56 square miles, was divided into five geographic strata before sampling was begun. Ten samples then were selected by the use of a table of random numbers and with proportional representation of each of the five strata. ${ }^{14}$ The fifth sample was used by Jamison ${ }^{9}$ for the study of periodontal disease. The population from which the sample was selected was defined as the noninstitutionalized residents. In an attempt to eliminate potential problems while conducting oral examinations of young children, only those persons who had reached the age of five years before November 1, 1959, were included in the dental study. There were 810 persons in the sample, of which 690 people participated in the study and received extensive dental examinations related primarily to periodontal disease.

The clinical examination consisted of a number of observations. In an attempt to make each observation as independent as possible from those preceding and following it, each assessment of the oral tissues was completed before the next assessment was begun for a given individual.

All permanent teeth which had erupted into occlusion were included in the study. If no antagonist were present, a given permanent tooth was included if it had erupted to what appeared to be the plane of occlusion. All other permanent teeth were designated as unerupted and no measurements were recorded for these teeth. In this investigation, therefore, the depths of the gingival sulci were determined around the young permanent teeth of 217 persons who ranged in age from six years, two months, to 18 years, eight months.

The measurements of the depths of the sulci were obtained by Jamison ${ }^{9}$ by using a University of Michigan No. 0 probe. This probe was selected because of its thin, round, blunt nib and its versatile angulation for probing the gingival crevices in all areas of the mouth.

The depth of the gingival sulcus of each tooth was measured at four locations, the distal, buccal, mesial and lingual surfaces. The measurements of the sulci at the mesial and distal surfaces of the tooth were obtained by placing the probe into each 
sulcus buccal to the area of contact and with the blade held parallel to the long axis of the tooth. The measurements obtained by Jamison and studied for this report represent the distance in millimeters from the free margin of the gingiva to the bottom of the sulcus. The periodontal probes used were graduated at three, six and eight millimeters from the end; it was necessary, therefore, to estimate measurements which fall between these graduations. All measurements were rounded to the nearest whole millimeter. In those instances in which the measurement appeared to be half millimeters, it was decided arbitrarily to round the half of the next lower whole number. This procedure was adopted knowing that the epithelial attachment was somewhat resilient and might tend to provide measurements of the depth of the sulcus which were in excess in the true depth.

In obtaining these measurements, Waerhaug's assertions ${ }^{22}$ were accepted, namely, that the bottom of the clinical sulcus is found at the deepest point of the epithelial attachment, which is at the cementoenamel junction. When a cushioned sensation was felt as the probe stopped, it was assumed that the epithelium was attached at the cemento-enamel junction and that this same junction had not been passed. If the probe encountered the cemento-enamel junction first (which was detected by a change in the direction of the tip of the probe as it moved from enamel to cementum), the exploration was continued deeper, until a cushioned sensation accompanied the stopping of the probe. It was assumed at this point that the base of the clinical sulcus had been reached.

\section{FINDINGS}

The mean depth of the sulci ranged from 1.12 millimeters on the buccal surface of a maxillary cuspid to 2.91 millimeters on the distal surface of a mandibular second molar. The accuracy of the measurement of the depth of the sulci at the distal surfaces of the maxillary second molars was questionable because it was difficult to obtain these measurements. In all instances, except maxillary second molars, the depth of the sulci at the mesial and distal surfaces was greater than the depth at the buccal and lingual surfaces by as much as one millimeter. This difference in depth may be illustrated by examining Tables 1-4; in all instances, the measurements secured at the buccal and lingual surfaces were shown graphically to be less for a greater percentage of the sample than those secured at the mesial and distal surfaces. These findings agree with those reported by Ramfjord, ${ }^{19}$ although the mean depth of the sulci in his study were slightly greater than those found in the present study. This difference might have been observed because almost all of the individuals examined by Ramfjord had periodontal disease, even though similar age groups were studied.

It also was found that the depth of the sulcus did not differ significantly between the corresponding teeth of a dental arch. To verify this conclusion, one tooth of each type, a molar, a bicuspid, a cuspid, and an incisor, was selected at random from the data of the left side of the mouth and compared with a similar sample from the right side. Table 5 shows that there was virtually no difference between the mean depths of the sulci on the right and left sides.

As a step in the processing of the data, a complete listing was prepared of the depth of the gingival sulcus at each surface of each tooth studied. By close inspection of these data, it appeared, as the age of the person increased, that the depth of the sulcus decreased in most mouths. The ages ranged from 6 years, 2 months to 18 years, 8 months.

To test an hypothesis about this observation, the number of people was determined who had each tooth in both the maxillary and mandibular right quadrants. Each such group then was divided about in half, taking care that a division did not occur between people whose ages were the 
Mandibular Right Central Incisor

Sample: 121 Teeth

Age: $\quad 6$ years, 9 months -12 years, 4 months

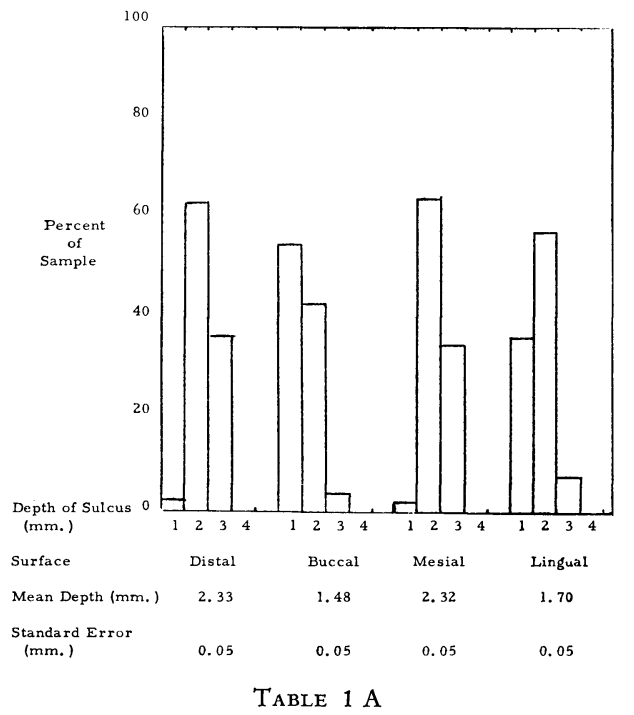

same month and year, but only between different months of the same year, or between different years. This division yielded two subgroups, according to age, a group of children (Table $1 \mathrm{~A}$ ) and a group of Maxillary Right Cuspid

Sample: 40 Teeth

Age: 11 years, 1 month - 14 years, 11 months

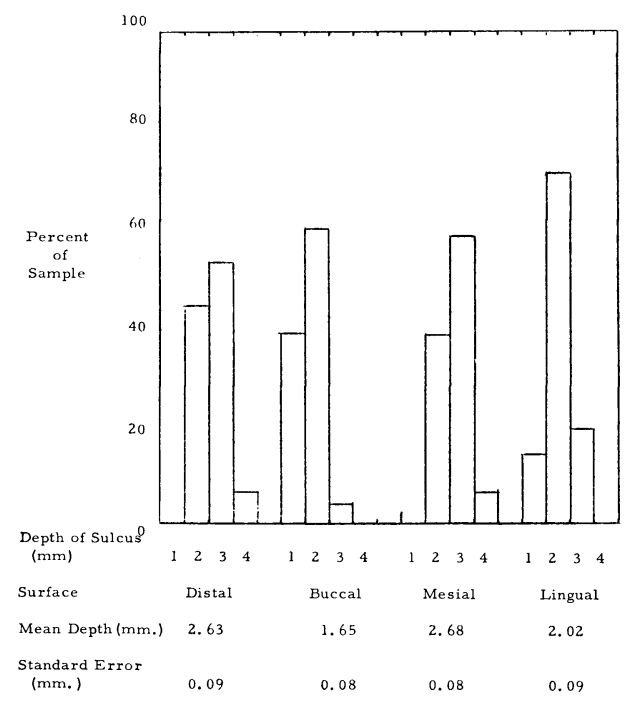

TABLE $2 \mathrm{~A}$

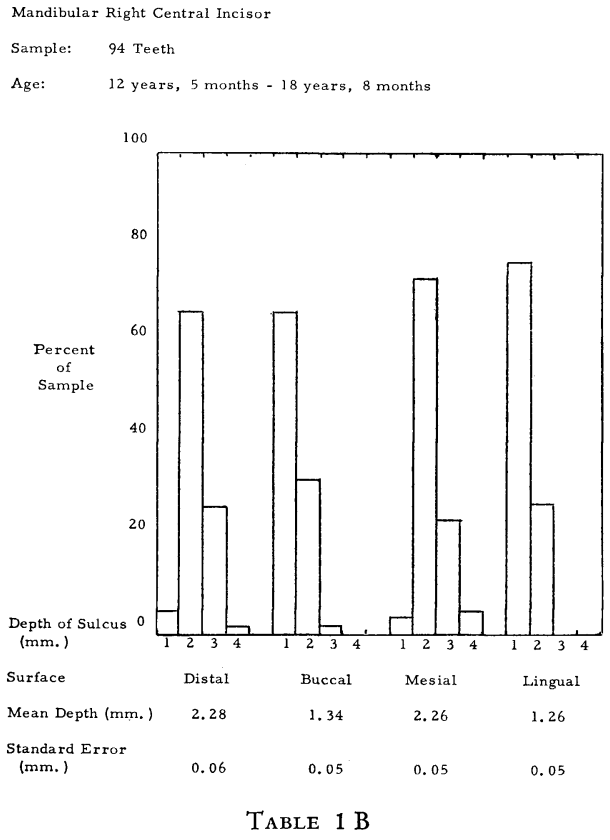

very young adults (Table $1 \mathrm{~B}$ ). The data from each of these groups were analyzed separately. This method of ten might yield subgroups of various sizes in which the span of ages could differ for each tooth

Maxillary Right Cuspid
Sample: $\quad 43$ Teeth
Age: $\quad 15$ years - 18 years, 8 months

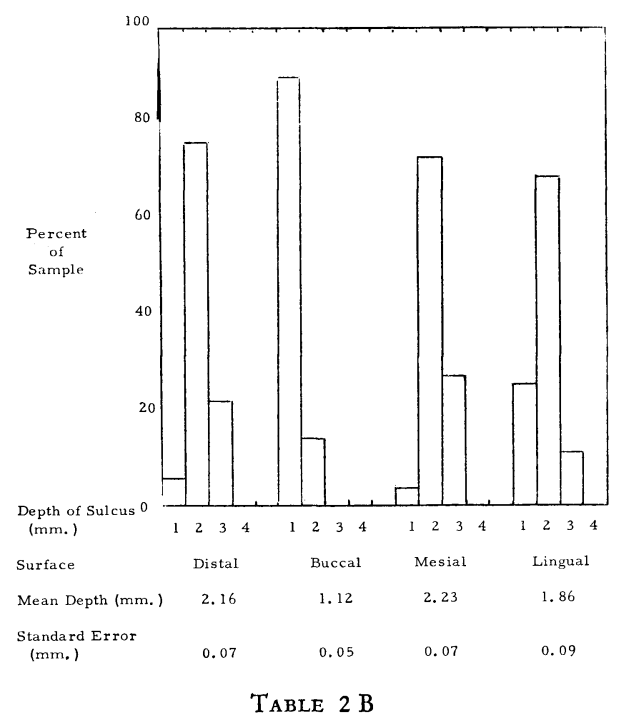




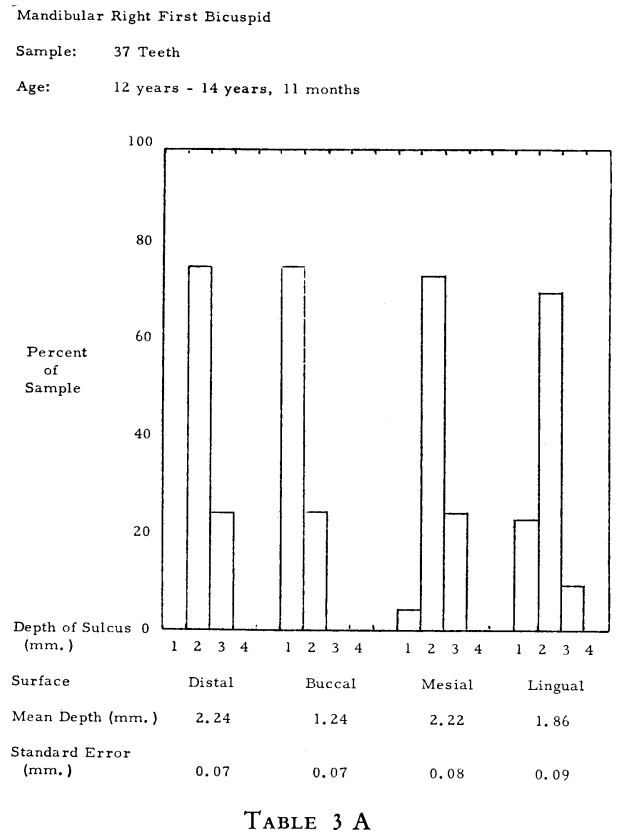

studied, however, for the first and second bicuspids identical age groups were compared. In a comparison of the mean depths of the sulci listed in Tables $1 \mathrm{~A}$ and $1 \mathrm{~B}$, it became evident that the mean depth of the sulcus decreased as the age of the children

Maxillary Right First Molar

Sample: 108 Teeth

Age: $\quad 6$ years, 2 months -12 years, 2 months

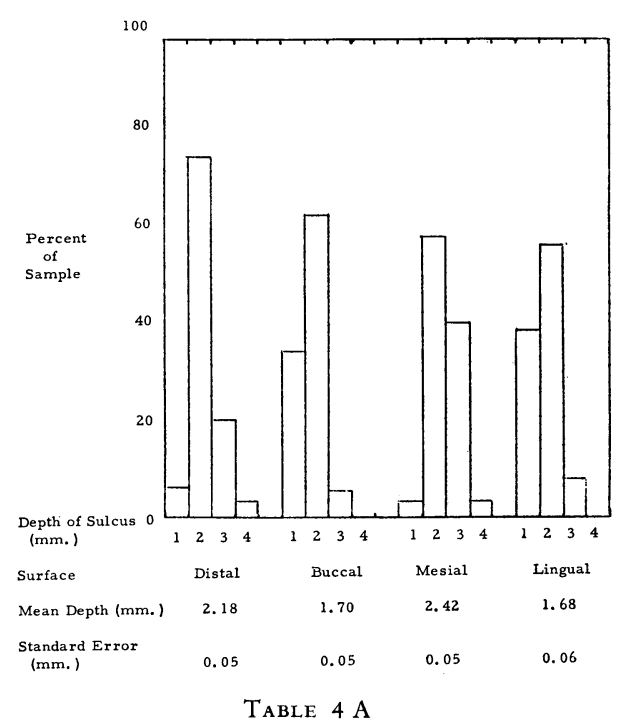

Mandibular Right First Bicuspid

Sample: 44 Teeth

Age: $\quad 15$ years -18 years, 8 months

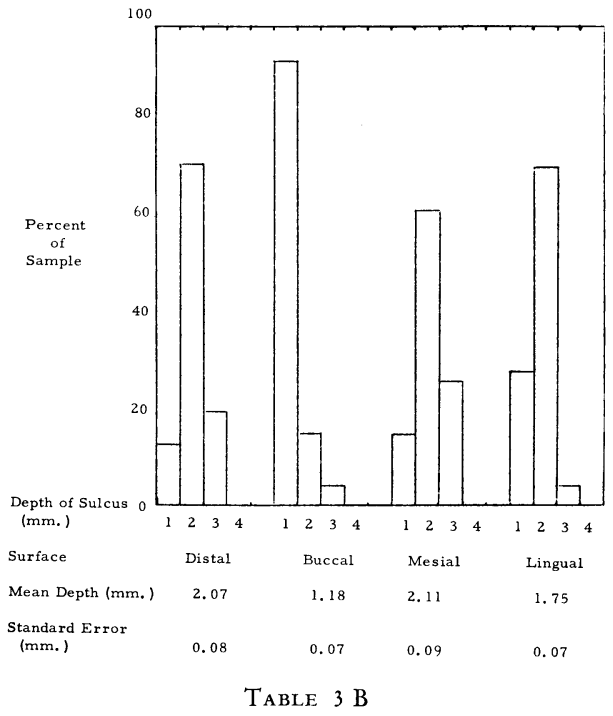

sample increased. A further comparison of Tables $2 \mathrm{~A}-4 \mathrm{~B}$ shows a decrease in mean depth in the older-age groups in every instance, frequently by almost one-half millimeter. For certain surfaces, there was a decrease of the mean depth by about 25

Maxillary Right First Molar

Sample: $\quad 97-98$ Teeth

Age: 12 years, 6 months -18 years, 8 months

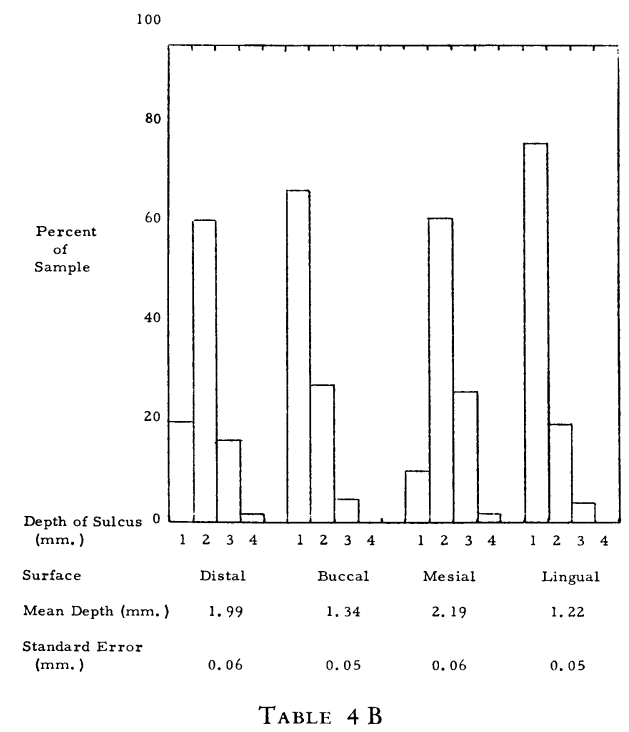


percent (Tables $2 \mathrm{~A}$ and $2 \mathrm{~B}$ ). Examination of the data verified what had appeared evident by inspection; the depth of the gingival sulcus decreased during adolescence.

\section{DISCUSSION}

As stated previously, the mean depth of the gingival sulci ranged from 1.12 to 2.91 millimeters. In all of the measurements obtained by Jamison, ${ }^{9}$ the crevicular depth recorded was found to be at least one millimeter. It will be recalled that estimations between graduations on the probe were rounded to the nearest whole millimeter and that when the measurements appeared to be in half-millimeters, they were rounded to the next lower whole number. The statement, therefore, should be that the shallowest depth was more than one-half millimeter. In Tables $1 \mathrm{~A}-4 \mathrm{~B}$, it became apparent that for the mesial and distal surfaces, most of the measurements of depth were two millimeters. Even on the buccal and lingual surfaces, where the crevices usually were less in depth than on the proximal surfaces, frequently, most of the measurements were two millimeters.

Orban and Kohler ${ }^{16}$ reported that more than 75 percent of their measurements of the gingival sulci were one millimeter or less in depth. More than four percent had zero depth of crevices. Neither the type of tooth nor the surface of the tooth, were stated and the type of instrument used to measure the depths of the sulci was not stated.

Three other investigators ${ }^{12,19,20}$ stated that zero depth of crevice was ideal; al- though without citing data to substantiate this conclusion. Because of the observations from the present investigation, the assertion that a zero depth of crevice is ideal may be questioned. It is difficult to accept pathological deepening in all of the gingival sulci of 217 persons, approximately six to 18 years of age.

It was stated earlier in this report that the assertions of Waerhaug ${ }^{22}$ had been accepted and used as a guide in the interpretation of the sensations felt while probing the gingival sulci. Waerhaug confirmed by radiograph the location of the tip of his probe at the cemento-enamel junction when forces of less than five grams were applied. Yet, Orban and Mueller ${ }^{17}$ stated that an explorer could not be pushed freely to the cemento-enamel junction. It was stated later by Orban, et al., ${ }^{18}$ that Waerhaug's insertion of the steel blade to the cemento-enamel junction caused a break in the epithelium and, thereby, destroyed part of the epithelial attachment. It is difficult to understand, however, that forces of a few grams which Waerhaug used, could separate the epithelium and the enamel to which Orban and his colleagues stated it was attached firmly and organically. Kohler and Ramfjord ${ }^{10}$ found that a sharp-pointed probe should not be used for measuring the depth of the crevice and that the depth of the sulcus always should be measured before anesthesia is induced. When these precautions were not observed, the probe was found to have passed the cementoenamel junction and penetrated apically in connective tissue to the alveolar crest.

To conclude that a very shallow gingival

TABLE 5

A Comparison in Millimeters of the Mean Depth of Sulci of Right and Left Dental Arches

\begin{tabular}{lccccccccc}
\hline \multirow{2}{*}{ Tooth } & \multicolumn{3}{c}{ Distal } & \multicolumn{2}{c}{ Buccal } & \multicolumn{2}{c}{ Mesial } & \multicolumn{2}{c}{ Lingual } \\
& Sample & $R$ & $L$ & $R$ & $L$ & $R$ & $L$ & $R$ & $L$ \\
\hline Maxillary Central Incisor & 94 & 2.29 & 2.47 & 1.44 & 1.50 & 2.45 & 2.37 & 1.86 & 1.84 \\
Mandibular Cuspid & 44 & 2.32 & 2.25 & 1.32 & 1.27 & 2.32 & 2.34 & 1.68 & 1.80 \\
Mandibular Second Bicuspid & 33 & 2.27 & 2.23 & 1.36 & 1.42 & 2.18 & 2.32 & 1.88 & 1.94 \\
Maxillary First Molar & 108 & 2.18 & 2.21 & 1.70 & 1.55 & 2.42 & 2.40 & 1.68 & 1.68 \\
\hline
\end{tabular}


sulcus exists must depend largely upon one's assumptions regarding the epithelial attachment. Denying or accepting the presence of an epithelial attachment is not a part of this report. One may question, however, Gottlieb's assertion that the epithelial attachment can be bound firmly to enamel, when based on two histological sections only. ${ }^{7}$ From these same two sections, one must keep in mind that Gottlieb "illustrates" the base of the gingival crevice. The area which Gottlieb and others ${ }^{17,20}$ designated as the base of the sulcus was actually the point at which the separation of epithelium from the tooth during the decalcification procedure ended, as described by Waerhaug. ${ }^{21}$

\section{CONCLUSIONS}

In this study of the depth of the gingival sulcus surrounding young permanent teeth:

1. The mean depth of the gingival sulci varied from 1.12-2.91 millimeters;

2. The depth of the sulci at the mesial and distal surfaces of the teeth was greater, by as much as one millimeter, than the depth at the buccal and lingual surfaces;

3. There were no significant differences in depth between the sulci around corresponding teeth of the right and left sides of the mouth;

4. The average depth of the sulci decreases at all surfaces of the teeth during adolescence.

\section{BIBLIOGRAPHY}

1. Beube, F. E. Periodontology. New York, Macmillan, 1953. XV + 752 p. (p. 6-12)

2. Black, G. V. Special dental pathology. Chicago, Medical Book Publishing, 1915. XXVIII + 489 p. (p. 22-9)

3. Bodecker, C. F., and Applebaum, Edmund The clinical importance of the gingival crevice. Dent. Cosmos, 76:1127-42, Nov. 1934.

4. Bodecker, C. F., and Lefkowitz, William. Gingival reattachment to the enamel and its relation to operative dentistry. Dent. Cosmos, 77:1106-14, Nov. 1935.

5. Glickman, Irving. Clinical periodontology.
Philadelphia, Saunders, 1958. XVII +978 p. (p. 9-29)

6. Goldman, H. M., and Cohen, D. W. Periodontia. St. Louis, Mosby, 1957. 535 p. (p. 24-37)

7. Gottlieb, B. Der epithelansatz am zahne. Deutch. Monatschr. Zahnhk., 39:142-7, Mar. 1921.

8. What is a normal pocket? Am. Dent. A.J., 13:1747-51, Dec. 1926.

9. Jamison, H. C. Prevalence and severity of periodontal disease in a sample of the population. Ann Arbor, The University of Michigan, School of Public Health, 1960. 153 p. thesis.

10. Kohler, C. A., and Ramfjord, S. P. Healing of gingival mucoperiosteal flaps. Oral Surg., Oral Med. and Oral Path., 13:89-103, Jan. 1960.

11. Kronfeld, Rudolf. The epithelial attachment and the so-called Nasmyth's membrane. Am. Dent. A.J., 17:1889-907, Oct. 1930.

12. - Histopathology of the teeth. $3 \mathrm{rd}$ ed. Philadelphia, Lea and Febiger, 1949. 514 p. (p. 294-315)

13. Miller, S. C. Textbook of periodontia. Philadelphia, Blakiston, 1950. XVIII + 900 p. (p. 39-47, 619-20)

14. Napier, J. A. Field methods and response rates in the Tecumseh Community Health Study. Am. J. Pub. Health, 52:208-16, Feb. 1962.

15. Noyes, F. B. Dental histology and embryology. Philadelphia, Lea and Febiger, 1921. VIII + 454 p. (p. 244)

16. Orban, B., and Kohler, J. Die physiologische zahnfleischtasche. Epithelansatz und epitheltiefenwucherung. Ztschr. f. Stomat., 22:353-425, 1924.

17. Orban, Balint, and Mueller, Emil. The gingival crevice. Am. Dent. A.J., 16:1206-42, July 1929.

18. Orban, Balint, et al. The epithelial attachment. J. Periodont., 27:167-80, July 1956.

19. Ramfjord, S. P. The periodontal status of boys 11 to 17 years old in Bombay, India. J. Periodont., 32:237-48, July 1961 .

20. Skillen, W. G.; and Mueller, Emil. Epithelium and the physiologic pocket. Am. Dent. A.J., 14:1149-64, July 1927.

21. Toller, K. J. R. The gingival sulcus and the epithelial attachment. Brit. Dent. J., 82:255-60, June 18, 1948. 85:1-7, July 2, 1948.

22. Waerhaug, Jens. The gingival pocket. Oslo, Reistad and Sonns, 1952. 186 p. (Odont. Taskr., vol. 60,1952 , Supplementum 1.)

23. Wheeler, R. C. A textbook of dental anatomy and physiology. 2nd ed. Philadelphia, Saunders, 1950. XIII + 428 p. (p. 32)

24. Zander, H. A. A method for studying "the epithelial attachment." J. Dent. Res., 35:308-12, Apr. 1956. 